\title{
SERUM S-100 PROTEN RELEASE AND NEUROPSYCHOLOGIC OUTCOME DURING CORONARY REVASCULARIZATION ON THE BEATING HEART: A PROSPECTIVE RANDOMIZED STUDY
}

Clinton T. Lloyd, FRCS ${ }^{a}$

Raimondo Ascione, $\mathrm{MD}^{\mathrm{a}}$

Malcolm J. Underwood, FRCS ${ }^{\text {a }}$

Freda Gardner, PhD, CPsychol ${ }^{\mathrm{a}}$

Andrew Black, FRCA ${ }^{\mathrm{b}}$

Gianni D. Angelini, FRCS ${ }^{\mathrm{a}}$
Objectives: Our purpose was to establish whether coronary revascularization on the beating heart without cardiopulmonary bypass is less harmful to the brain than conventional surgery with cardiopulmonary bypass as indicated by measures of cognitive function or by changes in serum concentrations of $\mathbf{S - 1 0 0}$ protein, a recognized biochemical marker of cerebral injury. Methods: We conducted a prospective randomized trial in which the assessors of the outcome measures were blind to the treatment received. Sixty patients without known neurologic abnormality, undergoing coronary revascularization, were prospectively randomized to 1 of 2 groups: (1) cardiopulmonary bypass $\left(32^{\circ} \mathrm{C}-34^{\circ} \mathrm{C}\right)$ and cardioplegic arrest (on pump) with intermittent antegrade warm blood cardioplegia or (2) surgery on the beating heart (off pump). Neuropsychologic performance was assessed before and 12 weeks after the operation. Serum S-100 protein concentration was measured at intervals up to 24 hours after the operation. Results: The groups had similar preoperative characteristics. There were no deaths or major neurologic complications in either group, nor was there any difference between groups in the chosen index of neurologic deterioration. Serum S-100 protein concentrations were higher in the on-pump group at 30 minutes, but any such difference between groups had disappeared 4 hours later. The extent of the changes in S-100 protein was unrelated to the index of neuropsychologic deterioration. Conclusions: The changes in S-100 protein concentration suggest that the brain and/or blood-brain barrier may be more adversely affected during coronary artery surgery with cardiopulmonary bypass than during surgery on the beating heart, but that this may not be reflected in detectable neuropsychologic deterioration at 12 weeks. (J Thorac Cardiovasc Surg 2000;119:148-54)
C oronary artery bypass grafting (CABG) with cardiopulmonary bypass (CPB) is a safe, routine procedure with a mortality of $2 \%$ to $3 \%$ in elective cases. ${ }^{1}$ Nevertheless, it is still associated with significant morbidity, mostly because of the cytokine response to the nonphysiologic nature of CPB., ${ }^{2,3}$ Although gross cere-

From the Bristol Heart Institute ${ }^{\mathrm{a}}$ and Department of Anaesthesia, ${ }^{\mathrm{b}}$ University of Bristol, Bristol Royal Infirmary, Bristol, United Kingdom.

This work was supported by the Sir Siegmund Warburg's Voluntary Settlement Fund and the British Heart Foundation.

Received for publication May 14, 1999; revisions requested July 26, 1999; revisions received Sept 2, 1999; accepted for publication Oct 7, 1999.

Address for reprints: Gianni D. Angelini, FRCS, Bristol Heart Institute, Bristol Royal Infirmary, Bristol, BS2 8HW, United Kingdom (E-mail: G.D.Angelini@ bristol.ac.uk).

Copyright (C) 2000 by Mosby, Inc.

$0022-5223 / 2000 \$ 12.00+0 \quad \mathbf{1 2 / 1 / 1 0 3 5 2 0}$ bral events such as stroke are rare, between $2 \%$ and $6 \%$ of patients have some form of neurologic injury in the initial perioperative period. In addition, subtle neuropsychologic changes develop in $20 \%$ to $60 \% .^{4,5}$ These changes in cognitive function may persist with an incidence of $25 \%$ to $30 \% 8$ weeks after the operation, with only slightly lower levels at 1 year. ${ }^{6}$ The mechanisms of these deleterious effects of CPB on the central nervous system are multifactorial. These include hypoperfusion during $\mathrm{CPB},{ }^{7}$ microemboli of a gaseous or particulate origin, ${ }^{8}$ or inflammatory changes that effect an increase in permeability across the blood-brain barrier with resultant cerebral edema. ${ }^{9,10}$

A number of biochemical markers have been suggested in an attempt to quantify the neuronal injury at the time of insult, among them protein S-100. This is an acidic, calcium-binding protein found in high concentrations in glial and Schwann cells. ${ }^{11}$ The appearance of 
this protein in serum indicates both neuronal damage and increased permeability of the blood-brain barrier.

Recently, interest in coronary revascularization on the beating heart has been revived, with the suggestion that avoidance of CPB may reduce neuropsychologic damage. There are, however, no data available as part of a prospective randomized trial on the possible relation between a recognized marker of ischemic brain injury such as protein S-100 and neuropsychologic outcome in patients undergoing elective $\mathrm{CABG}$ with or without CPB.

\section{Methods}

Patient selection. With approval from the local research ethical committee, 60 patients undergoing first-time CABG were enrolled in the study. They were part of a larger prospective randomized study comparing on-pump and off-pump surgery. From July 1997 to July 1998, 246 patients underwent first-time CABG under the supervision of a single consultant (G.D.A.). During this period 127 patients were eligible for randomization. Two patients refused to consent on personal grounds. Of the 125 remaining patients, 62 were randomized to on-pump and 63 to off-pump surgery. Thirty patients from each group were suitable for neuropsychologic studies. All patients were fully informed and signed consent forms. Exclusion criteria included cardiac ejection fraction of less than $30 \%$, myocardial infarction within the previous 1 month, disease involving the distal circumflex coronary artery, reoperation or combined valvular surgery, respiratory or renal impairment, and coagulopathy. Meticulous care was taken to exclude patients with previous psychiatric illness, previous stroke, or transient ischemic attacks, and any patient with suspected carotid artery disease underwent carotid duplex ultrasonography. The enrolled patients were prospectively randomized into 2 groups by card allocation: (1) on-pump group - conventional myocardial revascularization with $\mathrm{CPB}$ and cardioplegic arrest of the heart; (2) off-pump grouprevascularization on the beating heart.

Anesthetic technique. Anesthetic technique was standardized for all patients. This consisted of propofol infusion at 3 $\mathrm{mg} \cdot \mathrm{kg}^{-1} \cdot \mathrm{h}^{-1}$ combined with remifentanil infusion at 0.5 to $1 \mu \mathrm{g} \cdot \mathrm{kg}^{-1} \cdot \mathrm{min}^{-1}$. Neuromuscular blockade was achieved with 0.1 to $0.15 \mathrm{mg} \cdot \mathrm{kg}^{-1}$ of pancuronium or vecuronium and the lungs were ventilated to normocapnia with $45 \%$ to $50 \%$ oxygen in nitrogen. Propofol and remifentanil infusions were maintained throughout the operation. In the on-pump group, metaraminol or phentolamine was used as required to maintain the systemic pressure between 50 and $60 \mathrm{~mm} \mathrm{Hg}$. In the off-pump group, a mean arterial pressure of $60 \mathrm{~mm} \mathrm{Hg}$ or above was maintained with metaraminol or fluids as indicated by the hemodynamic condition. Esmolol was used as necessary to maintain the heart rate less than 65 beats/min.

Heparin and protamine management. In the on-pump group, heparin was given at a dose of $300 \mathrm{IU} \cdot \mathrm{kg}^{-1}$ to achieve a target activated clotting time (ACT) of 480 seconds or above before the start of CPB. In the off-pump group, a heparin dose of $100 \mathrm{IU} \cdot \mathrm{kg}^{-1}$ was given before the start of the first anastomosis. The target ACT in this group was between 250 and 350 seconds. Protamine was used at the end to reverse the effect of heparin and return the ACT to preoperative levels.

\section{Surgical technique}

On-pump group. CPB was instituted by means of ascending aortic cannulation and a 2 -stage venous cannulation via the right atrium. A standard CPB circuit was used consisting of a Bard tubing set (C. R. Bard, Inc, Santa Ana, Calif), which included a $40-\mu \mathrm{m}$ filter, a Stöckert roller pump (Sorin Biomedica, Midhurst, United Kingdom), and a hollow-fiber membrane oxygenator (Monolyth, Sorin Biomedica, Midhurst, United Kingdom). The extracorporeal circuit was primed with $1000 \mathrm{~mL}$ of Hartmann solution, $500 \mathrm{~mL}$ of gelofusine, a $0.5 \mathrm{~g} \cdot \mathrm{kg}^{-1}$ concentration of mannitol, $7 \mathrm{~mL}$ of $10 \%$ calcium gluconate, and $60 \mathrm{mg}$ of heparin. Nonpulsatile flow was used. The flow rate throughout bypass was $2.4 \mathrm{~L} \cdot \mathrm{m}^{2}$. $\mathrm{min}^{-1}$. Systemic temperature was allowed to vary between $32^{\circ} \mathrm{C}$ and $34^{\circ} \mathrm{C}$. Myocardial protection was achieved by means of intermittent antegrade warm blood cardioplegia as described by Calafiore and associates. ${ }^{12}$

Once all distal anastomoses had been completed, the aortic crossclamp was removed and the proximal anastomosis was carried out with partial clamping of the aorta.

Off-pump group. The method of exposure and stabilization used to carry out the distal anastomoses was a combination of the technique previously described by our group ${ }^{13}$ and the use of the CTS retractor (CardioThoracic Systems, Cupertino, Calif). ${ }^{14}$ The target vessel was exposed and snared above the chosen point for anastomosis by means of a 4-0 Prolene polypropylene suture (Ethicon, Inc, Somerville, NJ) with a soft piece of plastic "snugger" to prevent coronary injury. The coronary artery was then opened and the anastomosis performed with a continuous suture. Visualization was enhanced by a surgical blower-humidifier device (model SSVW-002; Surgical Site Visualization Wand; Research Medical Inc, Midvale, Utah) with a $1 / 4$-inch polyvinyl chloride gas line and fluid administration set connected to a regulated gas source of medical air. An intracoronary shunt (Anastoflo Intravascular Shunt; Research Medical Inc) was used only if there was appreciable electrocardiographic or hemodynamic instability or excessive bleeding during the construction of the anastomosis.

Samples for serum S-100 protein analysis. Blood samples $(4 \mathrm{~mL})$ were collected from the central venous pressure line at induction of anesthesia, 30 minutes after cessation of $\mathrm{CPB}$ in the on-pump group or 30 minutes after completion of all anastomoses in the off-pump group, and 4, 12, and 24 hours after the operation. The samples were centrifuged within an hour of collection to separate the serum, which was frozen and stored at $-20^{\circ} \mathrm{C}$.

S-100 protein assay. The S-100 immunoradiometric assay (Sangtec 100; Sangtec Medical AB, Bromma, Sweden) is a monoclonal 2-site immunoradiometric (sandwich) assay. The method discriminates between the $\alpha$-subunit and $\beta$-subunit 
Table I. Preoperative clinical data

\begin{tabular}{|c|c|c|c|}
\hline Variable & $\begin{array}{c}\text { On-pump } \\
\text { group } \\
(n=30)\end{array}$ & $\begin{array}{l}\text { Off-pump } \\
\text { group } \\
(n=30)\end{array}$ & $\mathrm{P}$ value \\
\hline Male & 27 & 26 & .7 \\
\hline Female & 3 & 4 & .7 \\
\hline Age $(y)$ & $62(56-69)$ & $59(54-64)$ & .1 \\
\hline Diabetes & 4 & 3 & .1 \\
\hline Extent of disease & & & .9 \\
\hline One-vessel disease & 5 & 6 & \\
\hline Two-vessel disease & 13 & 13 & \\
\hline Three-vessel disease & 12 & 11 & \\
\hline Angina class & & & .9 \\
\hline Grade I & 3 & 2 & \\
\hline Grade II & 17 & 16 & \\
\hline Grade III & 6 & 8 & \\
\hline Grade IV & 4 & 4 & \\
\hline Ejection fraction & & & .2 \\
\hline Good $(>50 \%)$ & 25 & 28 & \\
\hline Moderate (30\%-50\%) & 5 & 2 & \\
\hline Parsonnet score & $4(2-7)$ & $4(0-6)$ & .2 \\
\hline
\end{tabular}

Data are presented as medians with interquartile ranges.

( $\beta$-S-100 is present in high concentration in glial cells and Schwann cells) and measures the $\beta$-subunit of the S- 100 protein as defined by the 3 monoclonal antibodies SMST 12, SMSK 25 , and SMSK 28 . All samples were independently analyzed by Cambridge Life Sciences, Cambridge, United Kingdom.

Clinical and neuropsychologic assessment. The preoperative assessment included all of the usual clinical and investigation measures. The general level of risk for cardiac operations was expressed in terms of the New York Heart Association classification and Parsonnet's operative risk stratification. ${ }^{15}$ Postoperative neurologic status was assessed daily by clinical examination until the patient was discharged from the hospital. The patient's neurologic and neuropsychologic state was assessed a few days before the operation, to provide accurate baseline information, and 12 weeks after the operation. A suitably qualified and trained examiner, blinded to the surgical treatment, carried out the tests in a standardized manner. In accordance with the "Statement of Consensus on Assessment of Neurobehavioral Outcomes After Cardiac Surgery," 16 we subjected the patients to a battery of core tests that covered memory, language, psychomotor speed, attention, and concentration. This consisted initially of 2 tests from the Wechsler Memory Scale (WMS) and a battery of 5 neuropsychologic tests taken from the revised Wechsler Adult Intelligence Scale (WAIS). ${ }^{17}$ These are accepted tests of global cognitive function. The tests were presented in a fixed order according to conventional practice, and the scores were arranged such that larger scores indicated better neuropsychologic performance.

In addition, because cognitive function may be influenced by mood, ${ }^{16}$ each patient's current mental health was assessed by means of the General Health Questionnaire (GHQ-30) ${ }^{18}$ and Hospital Anxiety and Depression Scale (HAD). ${ }^{19}$
Statistical methods. As in our group's work in this area, ${ }^{17}$ the principal outcome measure of change in cognitive function for each patient was the number of neuropsychologic tests showing deterioration between baseline and the assessment 12 weeks after the operation. The numbers recruited were based on the requirement for $90 \%$ power to detect a difference of 1.18 scores, with an alpha error set at 0.05 . This was the same difference that we saw in our previous study ${ }^{17}$ between patients who received $\mathrm{CPB}$ perfusion at $32^{\circ} \mathrm{C}$ and those who received it at $37^{\circ} \mathrm{C}$. The difference in this measure between on-pump and off-pump groups was examined in a single variable model by means of the Student $t$ test and in a multivariable model to examine for the effects of any documented confounders. A stepwise multiple regression was undertaken, offering age, the changes in scores for Hospital Anxiety and Hospital Depression in the General Health Questionnaire, and the treatment (on pump or off pump) as explanators. This analysis, which examined only the direction of change without taking into account the magnitude, was supported by a multivariate analysis of variance (MANOVA), using a general linear model and offering age and the scores for Hospital Anxiety and Hospital Depression as possible confounders.

For effects on S-100 protein over time, the prospectively planned analysis was a repeated-measures analysis of variance (ANOVA), applied to the data from the 4 collection times after the preoperative sample. This was to examine for effects of time, group, and group-time interaction. When the data were obtained, the concentration values at most of the measurement times were not normally distributed, so that the probability estimates from the ANOVA were potentially unreliable. For supporting analyses, the area under the concentration curve (AUC) from the second sample time was calculated by triangulation as a summary measure for each patient. This measure was not normally distributed. A MannWhitney $U$ test was used to examine whether this measure varied between groups (on pump or off pump). Subsidiary Mann-Whitney testing was also undertaken on the concentrations at each sampling time. A Kruskal-Wallis test was used to examine for variation with the primary outcome variable (number of deteriorations in neuropsychologic scores) and a Spearman rank correlation to examine for variation with age.

All descriptive statistics and inferential testing were carried out by means of procedures in StatView (SAS Institute, Inc, Cary, NC) or Minitab 10.1 for Windows (Minitab Inc, State College, $\mathrm{Pa}$ ).

\section{Results}

Table I indicates the distributions of age, sex, extent of disease, left ventricular function, and number of grafts of the patients in each group. In the inferential testing that was undertaken to check on the effectiveness of the randomization, the only notable result was that the observed difference in age between the 2 groups was to be expected in only $5.4 \%$ of random allocations of this sort. None 
Table II. Operative and postoperative data

\begin{tabular}{|c|c|c|c|}
\hline Variable & $\begin{array}{l}\text { On-pump } \\
\text { group } \\
(n=30)\end{array}$ & $\begin{array}{l}\text { Off-pump } \\
\text { group } \\
(n=30)\end{array}$ & $\mathrm{P}$ value \\
\hline CPB time (min) & $72.9 \pm 28.3$ & & \\
\hline Crossclamp time (min) & $47.3 \pm 18.7$ & & \\
\hline Graft/patient (n) & $2.4 \pm 0.9$ & $2.2 \pm 0.9$ & .5 \\
\hline Graft distribution & & & .1 \\
\hline LAD graft (n) & 30 & 30 & \\
\hline Diag. graft (n) & 7 & 8 & \\
\hline RCA/PDA graft (n) & 15 & 16 & \\
\hline Cx territory graft $(n)$ & 20 & 13 & \\
\hline Stroke & 0 & 0 & 1.0 \\
\hline TIA & 0 & 0 & 1.0 \\
\hline Intubation time (h) & $11.2 \pm 7.5$ & $6.0 \pm 2$ & $.01^{*}$ \\
\hline ITU length of stay (d) & $1.3 \pm 0.6$ & $1.0 \pm 0.2$ & $.01^{*}$ \\
\hline $\begin{array}{l}\text { Postop. length of stay } \\
\text { (d) }\end{array}$ & $7.1 \pm 2.2$ & $5.8 \pm 1.5$ & $.01^{*}$ \\
\hline \multicolumn{4}{|c|}{$\begin{array}{l}\text { Data are presented as mean } \pm \text { standard deviation. } T I A \text {, Transient ischemic } \\
\text { attack; } L A D \text {, left anterior descending coronary artery; Diag, diagonal branch } \\
\text { of LAD; } R C A \text {, right coronary artery; } P D A \text {, posterior descending artery; } C x \text {, } \\
\text { circumflex artery. } \\
\text { "Statistical significance. }\end{array}$} \\
\hline \multicolumn{4}{|c|}{$\begin{array}{l}\text { Table III. Scores in General Health Questionnaire } \\
(G H Q) \text { and Hospital Anxiety and Depression (HAD) }\end{array}$} \\
\hline \multicolumn{2}{|c|}{$G H Q$} & HAD anxiety & HAD depression \\
\hline \multicolumn{4}{|l|}{ On-pump group } \\
\hline \multicolumn{4}{|c|}{$27(18-33)$} \\
\hline $12 \mathrm{wk}$ & 4-28) & $2(1-3)$ & $1(0-4)$ \\
\hline \multicolumn{4}{|l|}{ Off-pump group } \\
\hline Preop. & $1-34)$ & $6(3-9)$ & $4(2-5)$ \\
\hline $12 \mathrm{wk}$ & 3-27) & $4(2-5)$ & $2(1-3)$ \\
\hline
\end{tabular}

Data are presented as medians with interquartile ranges.

of the patients who were referred for duplex carotid ultrasonography had a carotid stenosis greater than $50 \%$. There were no deaths, major neurologic complications, or intraoperative myocardial infarctions in either group. Intubation time, intensive care stay, and length of hospital stay were significantly shorter in the off-pump group than in the on-pump group (Table II).

Numbers of deteriorations in neuropsychologic tests. Fig 1 shows the distributions of numbers of deteriorations in each group. The average number in the off-pump group was 2.13 (95\% confidence interval [CI] on mean 2.58-1.67) and 2.19 (95\% CI on mean $2.65-1.735)$ in the on-pump group $(P=.9)$. The stepwise multiple regression identified only the change in the depression component of the HAD score as a significant $(P<.03)$ explanator. The standard deviation of the regression coefficient was 0.05 . The regression

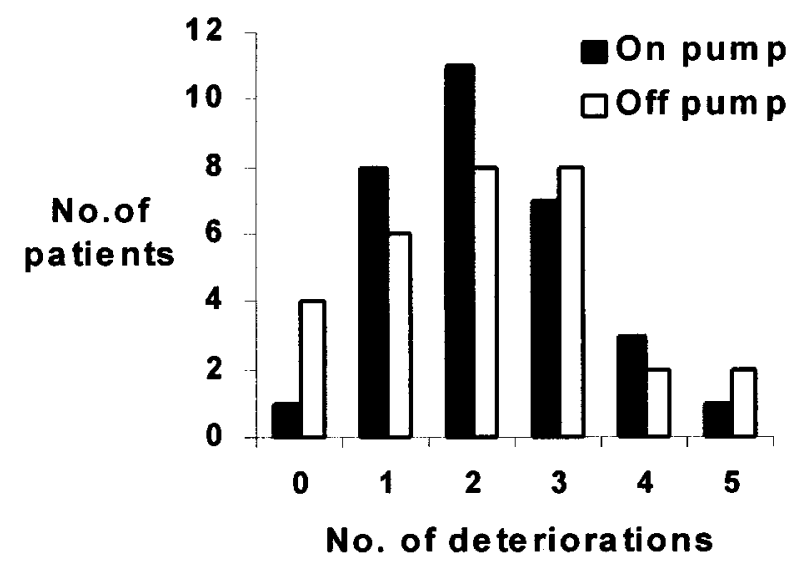

Fig 1. Deteriorations in neuropsychologic test score in the on-pump and off-pump groups.

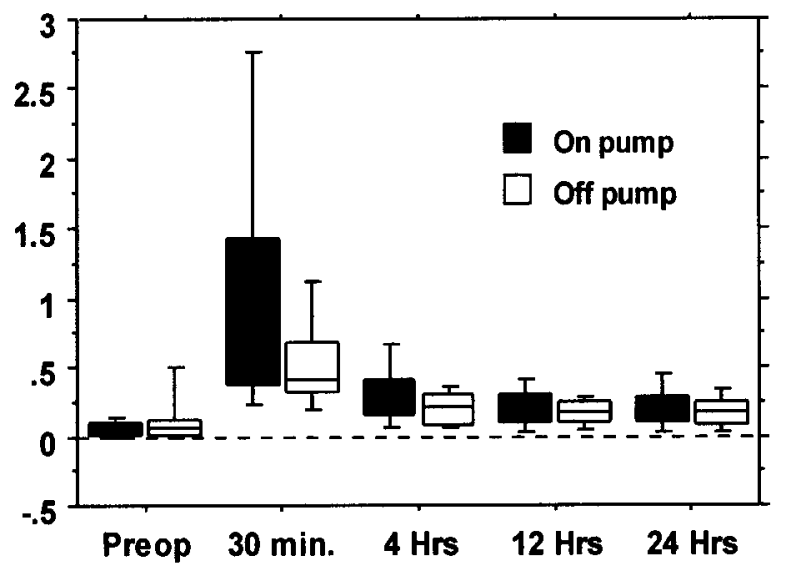

Fig 2. Serum S-100 protein levels (micrograms per liter) up to 24 hours after the operation in the on-pump and off-pump groups. Data are presented as medians with interquartile and total ranges.

explained only $7 \%$ of the variance of the primary outcome variable (coefficient of determination 0.07). The distributions for the GHQ and HAD scores are shown in Table III. The average preoperative and postoperative scores were similar for the 2 groups.

The MANOVA carried out on the 7 neuropsychologic scores confirmed the result indicated by the primary outcome variable in that there was no significant different difference between on-pump and off-pump groups in the magnitude of change across all 7 dimensions of outcome $(P=.18)$.

S-100 protein concentration. Fig 2 shows the distributions of S-100 protein concentrations in the 2 groups at the different sampling times, with "box and whisker" 
Table IV. Neuropsychologic deteriorations and area under the curve (AUC) of S-100 protein concentrations over time

\begin{tabular}{lccc}
\hline $\begin{array}{l}\text { No. of } \\
\text { deteriorations }\end{array}$ & $\begin{array}{c}\text { No. of } \\
\text { patients }\end{array}$ & $\begin{array}{c}\text { Median AUC } \\
\left(\mu \mathrm{g} \cdot h^{-1} \cdot L^{-1}\right)\end{array}$ & $\begin{array}{c}\text { Interquartile } \\
\text { ranges } \\
\text { of AUC }\end{array}$ \\
\hline 0 & 5 & 1.236 & $0.000-4.200$ \\
1 & 14 & 2.807 & $1.045-3.889$ \\
2 & 19 & 3.302 & $0.672-7.242$ \\
3 & 15 & 2.226 & $1.156-3.234$ \\
4 & 5 & 1.900 & $0.950-8.040$ \\
5 & 3 & 3.588 & $3.500-23.07$ \\
\hline
\end{tabular}

symbols used to indicate medians, interquartile ranges, and total ranges. The prospectively planned repeatedmeasures ANOVA identified a highly significant $(P=$ .02 ) effect of group (on pump or off pump) and a very highly significant effect of time $(P=.01)$ and group time interaction $(P=.02)$ (ie, the difference between groups depended on the sampling time). Testing at individual sampling times with Bonferroni correction showed a highly significant difference $(P=.01)$ at the 30-minute sampling time but not at subsequent sampling periods. The reliability of the $P$ values is called into question by the skewedness of the data, as indicated in Fig 2. Analysis of residuals showed significant non-normality in their distribution about the ANOVA model, and this could not be usefully reduced by a simple logarithmic transformation. The suspect findings of the repeated-measures ANOVA were supported by the difference in AUC of the S-100 protein concentrations between the 2 treatment groups. The median AUC in the on-pump group was $3.14 \mu \mathrm{g} \cdot \mathrm{h}^{-1} \cdot \mathrm{L}^{-1}$ with an interquartile range from 1.89 to 6.90 , whereas in the off-pump group it was 2.19 with an interquartile range from 0.80 to 3.52 (Mann-Whitney test, $P=.6$ ). The Bonferroni-corrected Mann-Whitney tests on the concentrations at each sampling time indicated that any difference in AUC was largely due to the difference in concentration at 30 minutes. Table IV shows the median AUCs and interquartile ranges in the groups characterized by number of neuropsychologic deteriorations. There was no obvious trend (Kruskal-Wallis test, $P=$ .2). The very large AUC in 1 of the 3 patients with 5 score deteriorations was in a patient whose baseline S100 concentrations were already high. The Spearman rank correlation for AUC with age was $0.507(P=.05)$.

\section{Conclusions}

Fundamental changes in the demographics of the cardiac surgical population have been observed over the past decade, mostly among patients undergoing CABG operations. Largely as a result of factors related to the increasing age of this group, major neurologic complications now constitute a growing percentage of serious postoperative morbidity. ${ }^{20-23}$ Furthermore, minor neurologic and neuropsychologic complications are reported to occur in up to $60 \%$ of patients in the first week after a cardiac operation and persist in one third of patients 6 months later. Given these adverse sequelae of CPB in terms of not only cerebral but also myocardial, renal, respiratory, and coagulation impairment, a revival of interest in performing $\mathrm{CABG}$ on the beating heart began in the early 1990s..$^{24-27}$ This technique has now faced and resolved most of the concerns regarding cardiac motion, anastomotic site exposure, number of grafts, and anastomosis quality. ${ }^{13,14}$ Recently, in a prospective randomized study, ${ }^{28}$ we showed preservation of myocardial function in off-pump compared with on-pump patients with less postoperative morbidity. Our study certainly found no major postoperative neurologic complications in either the on-pump or offpump group. However, there are inherent difficulties with the detection of functional subclinical problems such as cognitive dysfunction. A vast array of neuropsychologic tests exists to try to quantify these problems. We carried out our neuropsychologic assessment according to the "Statement of Consensus on Assessment of Neurobehavioral Outcomes After Cardiac Surgery." 16 We chose our outcome measure as the number of deteriorations in our bank of 7 neuropsychologic tests for the same reason that we chose it in our group's study ${ }^{17}$ of the effect of CPB temperature on cognitive performance. It was bound to be more sensitive than any of the existing binary measures based on the occurrence or not of "neuropsychologic deficit," defined in terms of whether or not a variously specified number of tests had deteriorated by a variously specified amount. Our present study showed no significant difference between the 2 groups in this measure of neuropsychologic outcome 12 weeks after the operation. The study achieved $90 \%$ power to detect a deterioration of the same size (1.18 scores) as we observed in our previous study ${ }^{17}$ between CPB perfusion at $32^{\circ} \mathrm{C}$ and $37^{\circ} \mathrm{C}$ (the clinical importance of which we could not determine).

Currently, serum S-100 protein is widely recognized as the most accurate biochemical marker of neuronal injury. ${ }^{5,8,11}$ The most conservative, nonparametric analysis of the serum S-100 protein concentrations over time gave only $94 \%$ confidence that there was a bigger rise in the on-pump group. Even the apparently more discriminating but also more suspect repeated- 
measures ANOVA indicated that any such difference had been measured only at 30 minutes after the operation and had essentially disappeared by 4 hours. Even if the existence of a short-lasting difference in S-100 protein concentrations between the on-pump and offpump groups is accepted, it is not necessarily attributable to the presence or absence of the pump. The randomization happened to produce a slight preponderance of relatively older patients in the onpump group, and the AUC of the S-100 protein concentrations tended to increase with increasing age. Both the association with age and the rapid disappearance of elevated postperfusion concentrations of S-100 protein are in accordance with observations by other authors. ${ }^{5,11,29}$ Westaby and associates ${ }^{5}$ speculated that the elevations reflect diffuse microembolic cerebral injury together with increased permeability of the blood-brain barrier rather than irreversible cerebral damage through neuronal ischemia. Their studies show a correlation of S-100 protein not only with the duration of CPB but also with the presence of carotid artery stenoses. ${ }^{8}$ The clearance of S-100 protein is reduced by reduction in glomerular filtration rate. This may be a plausible explanation for the transient rise in S-100 protein in the on-pump group, but further studies would need to confirm this. Our results may support the hypothesis that, at least in carefully selected, relatively young patients undergoing elective operations, with no previous history of neurologic injury, modern CPB causes only a transient loss of cerebral autoregulation with increased permeability of the blood-brain barrier resulting in temporary, functional rather than longterm, structural changes. It remains to be seen whether this is so in more elderly patients with pre-existing neurologic deficits.

We thank Amanda Burston for her invaluable help with the neuropsychologic testing and Simon Howell for his help in preparing this manuscript.

\section{REFERENCES}

1. Kirklin JK, Westaby S, Blackstone EH, et al. Complement and the damaging effects of cardiopulmonary bypass. J Thorac Cardiovasc Surg 1983;86:845-57.

2. Butler J, Rocker GM, Westaby S. Inflammatory response to cardiopulmonary bypass. Ann Thorac Surg 1993;55:552-9.

3. Steinberg J, Kapelanski D, Olson J, et al. Cytokine and complement levels in patients undergoing cardiopulmonary bypass. J Thorac Cardiovasc Surg 1993;106:1008-16.

4. Redmond JM, Greene PS, Goldsborough MA, et al. Neurologic injury in cardiac surgical patients with a history of stroke. Ann Thorac Surg 1996;61:42-7.

5. Westaby S, Johnsson P, Parry AJ, et al. Serum S100 protein: a potential marker for cerebral events during cardiopulmonary bypass. Ann Thorac Surg 1996;61:88-92.

6. Smith PLC. The cerebral consequences of coronary artery bypass surgery. Ann R Coll Surg Engl 1988;70:212-6.

7. Taylor KM. Cardiac surgery and the brain. In: Smith P, Taylor KM, editors. Cardiac surgery and the brain. London: Edward Arnold; 1993. p. 1-14.

8. Taggart DP, Bhattacharya K, Meston N, et al. Serum S-100 protein concentration after cardiac surgery: a randomised trial of arterial line filtration. Eur J Cardiothorac Surg 1997;11:6459.

9. Gillinov AM, Davis EA, Curtis WE, et al. Cardiopulmonary bypass and blood brain barrier: an experimental study. J Thorac Cardiovasc Surg 1991;104:1110-5.

10. Harris DNF, Baily SM, Smith PLC, et al. Brain swelling in first hour after coronary artery bypass surgery. Lancet 1993;342: 586-7.

11. Johnsson P, Lundqvist C, Lindgren A, Ferencz I, Alling C, Stahl E. Cerebral complications after cardiac surgery assessed by S-100 and NSE levels in blood. J Cardiothorac Vasc Anesth 1995;9: 694-9.

12. Calafiore AM, Teodori G, Mezzetti A, et al. Intermittent antegrade warm blood cardioplegia. Ann Thorac Surg 1995;59:398402.

13. Lucchetti V, Angelini GD. An inexpensive method of heart stabilization during coronary artery operation without cardiopulmonary bypass. Ann Thorac Surg 1998;65:1477-8.

14. Shennib H, Allan GL, Akin J. Safe and effective method of stabilization for coronary artery bypass grafting on the beating heart. Ann Thorac Surg 1997;63:988-92.

15. Parsonnet V, Dean D, Burnstein ED. A method of uniform stratification of risk for evaluating the results of surgery in acquired adult heart disease. Circulation 1988;79(Suppl):112.

16. Murkin JM, Newman SP, Stump DA, Blumenthal JA. Statement of consensus on assessment of neurobehavioral outcomes after cardiac surgery. Ann Thorac Surg 1995;59:1289-95.

17. Regragui I, Birdi I, Izzat MB, et al. The effect of cardiopulmonary bypass temperature on neuropsychologic outcome after coronary artery operations: a prospective randomized trial. J Thorac Cardiovasc Surg 1996;112:1036-45.

18. Goldberg D. Manual of the general health questionnaire. Berkshire [UK]: NFER-NELSON; 1976. p. 11-3.

19. Zigmond A, Snaith R. The hospital anxiety and depression scale. Acta Psychiatr Scand 1983;67:361-70.

20. Tardiff BE, Newman MF, Saunders AM, et al. Preliminary report of a genetic basis for cognitive decline after cardiac operations. Ann Thorac Surg 1997;64:715-20.

21. Wimmer-Greinecker G, Matheis G, Brieden M, et al. Neuropsychological changes after cardiopulmonary bypass for coronary artery bypass grafting. Thorac Cardiovasc Surg 1998:46: 207-12.

22. Benedict RH. Cognitive function after open-heart surgery: Are postoperative neuropsychological deficits caused by cardiopulmonary bypass? Neuropsychol Rev 1994;4:223-55.

23. Shaw PJ, Bates D, Cartlidge NE, et al. Early intellectual dysfunction following coronary bypass surgery. Q J Med 1986;58: 59-68.

24. Jansen EW, Borst C, Lahpor JR, et al. Coronary artery bypass grafting without cardiopulmonary bypass using the Octopus 
method: result in the first one hundred patients. J Thorac Cardiovasc Surg 1998;116:60-7.

25. Pfister AJ, Zaki MS, Garcia JM, et al. Coronary artery bypass without cardiopulmonary bypass. Ann Thorac Surg 1992;54:1085-92.

26. Benetti FJ, Naselli C, Wood M, et al. Direct myocardial revascularization without extracorporeal circulation: experience in 700 patients. Chest 1991;100:312-6.

27. Tasdemir O, Vural KM, Karagoz H, Bayazit K. Coronary artery bypass grafting on the beating heart without the use of extracor- poreal circulation: review of 2052 cases. J Thorac Cardiovasc Surg 1998;116:68-73.

28. Ascione R, Lloyd CT, Gomes WJ, et al. Beating versus arrested heart revascularization: evaluation of myocardial function in a prospective randomised study. Eur J Cardiothorac Surg 1999;15: 685-90.

29. Taggart DP, Mazel JW, Bhattacharya K, et al. Comparison of serum S-100 $\beta$ levels during CABG and intracardiac operations. Ann Thorac Surg 1997;63:492-6.

\section{Timely}

The Journal of Thoracic and Cardiovascular Surgery delivers the information you need now. Articles usually appear within four months of acceptance. 